\title{
The human side of mechanism design: a tribute to Leo Hurwicz and Jean-Jacques Laffont (Publisher's Erratum)
}

\section{Daniel McFadden}

Published online: 29 July 2009

(C) Springer-Verlag 2009

Erratum to: Rev. Econ. Design (2009) 13:77-100 DOI 10.1007/s10058-009-0075-x

In the title of this article there is a typing error in the name "Jean-Jacque Laffont", it should read "Jean-Jacques Laffont".

The online version of the original article can be found under doi:10.1007/s10058-009-0075-x.

D. McFadden $(\varangle)$

Department of Economics, University of California, Berkeley, CA 94720-3880, USA

e-mail: mcfadden@econ.berkeley.edu

URL: http://www.econ.berkeley.edu/ mcfadden/index.shtml 